\title{
Superkids: Short-Term Group Therapy for Children With Abusive Backgrounds
}

Patricia A. Morris, MS, RN, CS

\section{Many children who are hospitalized have a history}

of physical or sexual abuse. A short-term therapy

group for children with abusive backgrounds, called

Superkids, was led by nurse therapists using a com-

bination of active role playing, masks, picture draw-

ing, and discussion. The group was structured and

covered five topics over a $2 \frac{1}{2} 2$ week period: shame,

anger, fear, trust and love. Clinical observations sug-

gest that the Superkids group structure helps chil-

dren talk about their feelings and the abuse they

have suffered. Through a brief intervention group,

members learn they are not alone and that they are

accepted by their peers.

Accepted for publication July, 1992.
Patricia A. Morris, MS, RN, CS, is Director of Nursing, Barry Robinson Center, (a residential treatment facility for children and adolescents), Norfolk, VA. At the time this article was written, Ms. Morris was a Clinical Nurse III at the University of Michigan Hospital Children's Psychiatric Unit, Ann Arbor.

$\mathbf{N}$ iatric Inpatient Unit at the University of Michigan Medical Center, has shown that $64 \%$ of the children hospitalized have a history of physical or sexual abuse. Another $13 \%$ show symptoms of abuse but have no known history of abuse (Morris \& Bihan, 1991). During hospitalization is an excellent time for these children to receive treatment for the trauma they have suffered. The Children's Psychiatric Inpatient Unit is a short-term treatment unit; length of admissions range from two weeks to one month. Upon discharge from the unit children return to their families. In March 1990, nurse therapists on the unit started an educational support group called Superkids for children from abusive backgrounds. The purpose of Superkids was to help the children change their negative self-images and learn alternative ways of coping with their dysfunctional families.

A review of the literature uncovered numerous articles describing group therapy for adolescents with a history of abuse, but few for children. None of these groups ran less then three months and most of them lasted a year. No short-term group therapy for hospitalized children 4 12 years old with a history of abuse was found to use as a model. Therefore, a group was designed specifically for the children admitted to the unit, which took into consideration their developmental level and history of abuse.

Although no articles addressed short-term group therapy for sexually abused children, current literature existed on long-term group therapy for abuse and individual therapy for abused children. This literature was consulted to help determine the type of group therapy methods that would be most effective to use for children from this age group (Burgess, 1986; MoCausland \& Wolbert, 1981).

A combination of active role playing using masks or puppets, drawing pictures, and discussion of how the 


\section{Superkids: Short-Term Group Therapy for Children With Abusive Backgrounds}

abuse related to the children's own lives was determined appropriate (Walker, 1988; Haugaard, 1988; and Giaretto, 1981). Haugaard recommended focusing on particular themes when working with sexually abused children, such as anger and aggression, trust and safety, fear, feelings of being damaged goods, and role confusion. Faller (1988) identified treatment issues as loss of trust, altered body image, guilt feelings, anger, understanding the meaning of sexual abuse, and strategies for self-protection. Similar themes emerging from the literature surrounding physical abuse determined the topics to be used for this group: shame/blame, anger, fear, trust, and love (Faller, 1988; Haugaard, 1988; Giaretto, 1981). Although love was not identified as a theme by other authors, the author of this paper felt abused children were very unsure of what love was and how to express it appropriately. Thus, the author chose love as one of the topics.

\section{Group Structure}

Group members were chosen from the 4 to 12 -year-old children hospitalized on the Children's Psychiatric Inpatient Unit. Criteria for entry into the group were: (a) a history of physical and/or sexual abuse or symptoms of abuse; (b) ability to participate in the group without becoming aggressive physically or verbally to the other members or otherwise so dysfunctional their behavior made it impossible for them to function in a group; and (c) referral to the group by the primary nurse, individual therapist and/or co-leader.

The group, which was co-led by two nurses who worked on the unit, consisted of 4 to 6 girls and boys with similar levels of cognitive functioning. The group met twice a week for 30 to 45 minutes in the family group room off the unit. The group was open-ended with children coming and going depending on the admissions and discharges of the unit. Once a child joined the group, he or she remained a member until discharge from the hospital. Groups ran in a repeating cycle of five meetings, and covered the topics of shame/blame, anger, fear, trust, and love.

Each group session followed the same format. First the co-therapists role played a dysfunctional scene using masks or puppets that might be typical in the children's family life. The children then discussed the general emotional tone of the role playing or how the child or parent felt. They were asked to draw a picture of the emotion or of a similar scene from their family. They were also invited to share with the group their pictures or something similar that happened to them in their family. The therapists then role played the same scene but this time with the children responding in an alternative manner that created a more positive self-image for each child and that viewed the adults' behavior as dysfunctional. Then two children at a time took over the roles played by the co-therapists and repeated the scenario, performing the new alternative behavior. These children were rewarded with applause from their peers and stickers from the therapists. Finally, the group members briefly reviewed what they learned.

\section{Group Content}

When the group first met or a new child entered the group, members greeted them with a rap like, "Cowabunga dudes and dudettes. You've been invited to be a member of Superkids because we know you're a totally awesome dude. Sometimes children forget they are awesome because they have so many problems with their families but we're here to remember and help you remember that you are awesome. We're all from families so let's all draw a picture of our family."

The therapists and the children would then share with each other who the members of their family were. This introductory drawing served as an icebreaker, involving the children in a group process activity that was relatively low stress compared to other pictures they might draw later in the group. It also served as a tool to look at how the child viewed himself or herself as a member of his or her family and showed the children they had a common theme with the other children in the group-that they're all from families. This activity drew the children into their first speaking role in the group, when it came their turn to show their picture to the other children and tell who was in their family. The therapists kept all of the children's drawings in a book so the children could share them with each other when appropriate in future meetings. 
The therapists then showed the children the masks and puppets and talked about the emotions that could be demonstrated using the masks and puppets. Group rules were also discussed at this time: (a) Each child gets a turn to talk and everyone else must be quiet while the child is talking; (b) no physical or verbal aggression is allowed; and (c) each child shows the other child respect by paying attention when the other child role plays and by applauding at the end of the role play.

\section{Session 1. Shame/Blame}

\section{Therapists role play}

A mother and child are riding in the car on the way to the store. The child tells the mother that he or she has to go to the bathroom. The mother won't stop at the bathroom but insists the child has to hold it. The child wets his or her pants after repeatedly asking the mother to stop. The mother yells at the child and swats the child saying it's all the child's fault. The child cries and feels ashamed.

\section{Questions/Activities for discussion}

Who is to blame, the mother or the child?

How do you think the parent and child felt?

Can you give examples or draw a picture of a time when you felt ashamed or were blamed for something?

\section{Therapists repeat role play}

The parent acts the same, but the child finally tells the parent that he or she will wet the car seat if not allowed to stop. The child says it won't be his or her fault because he or she told the parent he or she couldn't hold it. The parent is able to stop then because he or she doesn't want the car seat wet.

\section{Questiona/Activities for discussion}

How do you think the child felt this time?

Can you think of any other thing the child could have done to help him/herself in this situation?

Can you role play the situation using the new strategies you've learned?

\section{Session 2 Anger}

\section{Therapists role play}

The children are fighting with each other over a toy. The mom comes into the room yelling at the children to stop. The children do not stop and the mom continues to yell, this time swatting each of the children, taking the toy and leaving the room. The children yell at each other and continue to fight.

\section{Questions/Activities for discussion}

What emotion was being displayed by the mother and the children in the role play?

Do you know anybody who has a problem with anger?

Can you draw a picture of what anger looks like in your family?

\section{Therapists repeat role play}

The parent acts the same as before but this time the children decide to cooperate rather then being angry with each other. One child tells the other to stop fighting because mom/dad is in a bad mood and remember what happened the last time. They got hit. The other child suggests they share the toys. The parent is then able to walk away from the children.

\section{Questions/Activities for discussion}

What did the children in the role play do differently this time?

How do you think the children felt about each other since they helped and supported each other?

Can you role play showing children helping each other so they don't get in trouble or get hit? 


\section{Superkids: Short-Term Group Therapy for Children With Abusive Backgrounds}

\section{Session 3. Fear}

\section{Therapists role play}

The mother awakens the father for work because he is late getting up. The father had drunk too much the night before and has a hangover. He's very grouchy, yelling at mom and knocking things about in the house. When he comes into the living room where the children are watching TV, he yells about the noise and turns off the TV as he walks out the door. The children huddle on the couch afraid and one of the children cries.

\section{Questions/Activities for discussion}

How do you think the children felt when the dad was yelling?

How do you think the mom felt?

Has this kind of situation ever happened in your house?

Can you draw a picture of yourself at a time when you felt scared?

\section{Therapists repeat role play}

This time the parents act the same but one child suggests to the other that they go to their rooms together to get away from the parent's anger. When the father comes into the room the children are already gone.

\section{Questiona/Activities for discussion}

What did the children in the role play do differently this time?

How do you think they felt?

Can you think of any place else the children could have gone to be safe?

Can you do the role play and keep the childnen safe?

\section{Session 4. Trust}

Therapists mole play

The child is waiting at the window for the father to come visit. The child is sad. The father has not shown up at the scheduled time. The child says to the mother that the father does not love the child. The child says, "I will never trust my father will come on the day he says." The mother replies, "You know your father."

Questions/Activities for discussion

How did the child feel?

Will the child trust the dad the next time?

Can you draw a picture or describe a time when you couldn't trust someone?

Therapists repeat role play

The parent acts the same but the child calls the father up this time and tells the father he or she is disappointed that the father didn't come and worried that the father doesn't love him or her. The father is then able to apologize and promises an alternative time to come. The child asks how he or she will know if the parent will come since the parent didn't come today. The child suggests the parent come over now; the parent agrees.

\section{Questions/Activities for discussion}

What did the child do differently in the tole play this time?

How do you think the child felt?

Can you role play a child telling the panent that he or she needs to show you can trust them? 


\section{Session 5. Love}

\section{Therapists role play}

The child tries to give the mother a picture that the child drew, but the mother is busy working on the computer and ignores the child saying, "I'm busy." The child tries several times but each time the mother ignores the child and finally the child withdraws and tears up the picture.

\section{Questions/Activities for discussion}

How did the child feel?

Why was the child trying to give the mother a picture? Have you ever been ignored when you were trying to give a parent some love or get some love from a parent?

\section{Therapists repeat role play}

The parent acts the same at first until the child tells the parent he or she is trying to give the parent love. Then the parent is able to tum around and accept the child's picture and thank the child.

\section{Questions/Activities for discussion}

What did the child do differently this time?

How did the child feel?

Can you do the role play in which a child says, I love you to the parent?

\section{Clinical Observations}

Children who are suffering from a past history of abuse need an opportunity to express the trauma they have experienced (Fredrick, 1986). The author found

that group members quickly began to disclose to the group the abuse they had suffered. It appeared that, simply by observing the short role plays, children knew this group was a place they could safely talk about their painful experiences. The therapists exerted no pressure upon the children to talk about the past. The group leaders asked only if any of them had something similar to the role play happen to them. Inevitably, one of the children would start talking about his or her past history of abuse and soon others would share as well.

Group therapy can give abused children the experience of knowing they are not alone in their experience and will not be ostracized by their peer group (Giaretto, 1981). When one little girl first came into group, she was very withdrawn, refusing to say anything at all. However, by the third session she made a one-sentence statement about having been abused, and drew a picture of herself, her abuser, and a wolf with sharp teeth and liquid flying from its mouth. When it came her turn to talk about her picture she pointed to herself and her father, identifying each one and described the wolf as anger. Shortly after group the author found her in her room and her roommate said, "My roommate just told me what her dad did to her when she was younger and that's really bad. We really have something in common because my dad has hurt me like that too."

To foster a greater sense of belonging and give new members a sense of hope, children who have been in the group the longest are asked to tell new members what group was about. Most often the children said that group was a place where you talk about your feelings and do role plays. Some children added that the group helps you remember you're a super kid or that, in the group, you talk about bad things that have happened to you. One boy who was very opposed to coming to group opened up 10 minutes into the session. He told the other children about his father being drunk and chasing him with a rope and that he feared for his life. When he drew his picture, he made a map showing where he had run the day his father was chasing him with the rope, described to the others how he felt, and talked about the neighbors who had helped him call the police. He con- 


\section{Superkids: Short-Term Group Therapy for Children With Abusive Backgrounds}

tinued to complain about coming to group but always attended.

Children frequently need to play and replay the trauma they have suffered to express the anger associated with abuse, provide cognitive structure, learn their own power and control, and develop new behavioral skills (Walker, 1988). Some of the children really enjoyed doing the role plays and used them as an opportunity to play out the abuse that had happened to them. One 11-yearold girl played out two abuse scenes that had happened when she was 4 and beaten by her alcoholic mother. She repeated these scenes for several group sessions.

Nonverbal outlets for expression of emotions are developmentally appropriate for preteen children. Researchers in the area of human figure drawings have found children draw anger and aggression in similar ways (Koppitz, 1984). A boy in the author's group refused to participate in role plays but willingly drew pictures each group session about his experiences or feelings. The pictures frequently contained aggressive scenes and the people in them had distorted or disturbed mouths. In fact, many of the children drew abusers or the abused with distorted mouths.

Sometimes children in the group did not have a known history of abuse, but the group leader noticed the youngsters displayed symptoms of abuse. These symptoms included sexual acting out, aggression, nightmares, pseudomaturity, above-age-level sexual knowledge, etc. Occasionally, one of these children would reveal a history of abuse in group, but many others never talked about their home life. The group leaders could only hope these children benefited from being included in the group.

The author and colleagues found the group had to be very fast paced and activity oriented to hold the children's attention. The running of the group had to be flexible to accommodate the wide range of children's abilities to attend and verbalize in the group setting. Sometimes the leaders ran two separate groups because several children were so low functioning intellectually either due to mental illness, mental retardation, or developmental stage that they were too disruptive to the older, more verbal children. Occasionally, the leaders would have a quiet, more depressed group of children that was easy to work with because they were able to sit still. Most of the time, the group consisted of 5 to 7 hyperactive children; occasionally, the leaders ended the group after thirty minutes because the children were getting out of control. In such cases, the leaders found that one of the children in the group was unable to control himself or herself, then the leaders sat next to the child and touched him or her on the arm occasionally, making sure the child had a turn to verbalize and set limits on interruptions while others were speaking. Once, one of the co-therapists had to leave group with a child who became increasingly agitated as others talked about being physically abused. The child began hitting himself and talking to himself and was not able to settle down while in the group setting.

Although therapists worked individually with children in the inpatient setting, they had far better success getting the youngsters to talk about their past abuserelated traumas in the group setting. The author and colleagues kept in close contact with the children's individual therapists to let them know what issues the children were talking about in the group setting. The group leaders communicated with the therapists by writing in the interdisciplinary progress notes on each child after each group session and by reporting in team meetings on individual children. The group leaders also directly sought out the child's therapist, if they felt the information the child revealed in the group was of particular significance to the child's illness. Therapists familiar with the group frequently asked to have the child they were working with included in group. Some therapists made special requests about helping a particular child with an abuse issue they were seeing in individual therapy.

Nurses on the children's unit viewed the Superkids group as a valuable tool in helping to treat children from abusive backgrounds. Each time a children's group was held, nurses on the unit were willing to help care for the children who were not involved in group to free the group leaders of other responsibilities. Occasionally, the unit milieu was in such an agitated state at the time the group was supposed to meet that it was difficult or 
impossible to free up the co-therapist nurses to run group. The nurses on the children's unit found it easier to hold the group when the education nurse in charge of the group did not have a patient assignment.

\section{Conclusion}

The American Nurses Association's Standards of Child and Adolescent Psychiatric and Mental Health Nursing Practice (1985) states, "The nurse uses psychotherapeutic interventions to assist children or adolescents and families to develop, improve or regain their adaptive functioning, to promote health, prevent illness, and facilitate rehabilitation" (p.14). The psychiatric nurse helping the child recover from the trauma of physical and sexual abuse has a definite role in assisting the child to regain adaptive functioning. Structured short-term group therapy for children psychiatrically hospitalized with a history of abuse can help the child regain adaptive functioning and facilitate rehabilitation. The children who were involved in Superkids were able to express their feelings and play out their trauma from the past. They learned they were not alone in the abuse they had suffered and were accepted by their peer group and the adults in the therapy sessions. They had an opportunity to practice new behaviors that offered them control over their environments.

The co-therapist nurses who were running Superkids proposed several useful research projects for the group. One was to utilize a pretest and posttest tool for children in the group, to determine what benefits they received from being in the group.

In order to conduct a program evaluation to determine the actual patient outcomes of such a group experience, a number of strategies could be utilized. Norwicki's Locus of Control Scale for Children (1973) could be used to determine if the children felt they were in control or if control came from the outside. This tool can assist the group leaders to determine if being in the children's group affected the children's perception of having control of their world. Another tool to be considered is the Piers-Harris Children's Self-Concept Scale (1984) to see if the children in the group improve in self-esteem after being in group.
Koppitz's Emotional Indicators On Human Figure Drawings (1984) can also be used to look at the drawings the children made in group to see if they duplicated Koppitz's findings. The author and co-therapists did informally look at the drawings and saw pictures that were similar to Koppitz's findings around aggression. Many questions need to be answered in order to advance nursing's knowledge related to the treatment of abuse and both time and resources need to allotted to ensure that evaluation and research take place.

\section{References}

American Nurses Association. (1985). Standards of child and adolescent psychiatric and mental health nursing practice. Kansas City, MO: Author.

Burgess, A. (1986). Youth at risk: Understanding runaway and exploited youth. Washington, DC: DHHS, National Center for Missing and Exploited Children.

Faller, K. (1988). Child sexual abuse: An interdisciplinary manual for diagnosis, case management, and treatment. New York: Columbia University Press.

Fredrick, C. (1981). Post traumatic stress disorder and child molestation. Sexual Medicine, 4, 32-40.

Giaretto, H. (1981). A comprehensive child sexual abuse treatment program. International Journal of Child Abuse and Neglect, 6, 263-278.

Haugaard, J. (1988). The sexual abuse of children: A comprehensive guide to current knowledge and intervention strategies. San Francisco: Jossey-Bass.

Koppitz, E. (1984). Psychological evaluation of human figure drawings. New York: Grune \& Stratton.

McCausland, M., \& Wolbert, W. (1981). Children's drawings as indicators of sexual trauma. Perspectives in Psychiatric Care, 9(2), 50-58.

Morris, P., \& Bihan, S. (1991). The prevalence of children with a history of sexual abuse hospitalized in the psychiatric setting. Journal of Child and Adolescent Psychiatric and Mental Health Nursing, 4(2), 49-54.

Norwicki, J., \& Strickland, S. (1973). A locus of control scale for children. Journal of Consulting and Clinical Psychology, 50(1), 148-154.

Piers, E, \& Harris, D. (1984). Piers-Harris children's self-concept scale. Los Angles: Western Psychological Services.

Walker, L. (1988). Handbook on sexual abuse of children: assessment and treatment issues. New York: Springer. 